\title{
DESENVOLVIMENTO E IMPLEMENTAÇÃO DE UM GUIA DE PADRÃO DE QUALIDADE PARA A PRODUÇÃO DE OBJETOS DE APRENDIZAGEM NA EDUCAÇÃO A DISTÂNCIA DO INSTITUTO FEDERAL DE EDUCAÇÃO CIẾNCIA E TECNOLOGIA DO RIO DE JANEIRO (IFRJ)
}

\author{
Lígia Moura Simões de Souza ${ }^{1}$ \\ UFRRJ \\ ligiamssouza@gmail.com \\ Saulo Barbara de Oliveira ${ }^{2}$ \\ UFRRJ \\ saulobarbara@gmail.com
}

\begin{abstract}
Resumo
A educação a distância é uma modalidade de ensino em plena expansão devido a sua capilaridade e capacidade de inovação. No entanto, a elaboração de um curso a distância requer ampla utilização das tecnologias da informação e comunicação (TIC) e demanda novos formatos que contemplem a interatividade. Este artigo contextualiza a produção de objetos de aprendizagem $(\mathrm{OA})$ na educação a distância $(\mathrm{EaD})$ dos Institutos Federais. Com o objetivo de identificar padrões de qualidade considerados na produção de OA, foi realizada uma análise qualitativa recorrendo-se às pesquisas documental e bibliográfica realizadas por meio de estudo bibliométrico, além da coleta de dados por meio de 36 entrevistas semiestruturadas com estudantes, técnicos e gestores EaD na Rede Federal. Utilizando como método o estudo de caso e a técnica de análise de conteúdo, foram alcançados os seguintes resultados: (a) realização de diagnóstico sobre o problema; (b) recomendações de melhorias; (c) elaboração de plano de ação para implementação de padrões de qualidade para produção de videoaulas no Ambiente Virtual de Ensino e Aprendizagem do Instituto Federal de Educação, Ciência e Tecnologia do Rio de Janeiro (IFRJ). Nesse artigo, discutimos resultados alcançados.
\end{abstract}

Palavras-chave: Educação a istância (EaD). Gestão da qualidade. Objeto de aprendizagem. Videoaula. TIC.

\section{DESIGN AND IMPLEMENTATION OF QUALITY CONTROL MODEL FOR DEVELOPING LEARNING OBJECTS IN INSTITUTO FEDERAL DE EDUCAÇÃO, CIÊNCIA E TECNOLOGIA DO RIO DE JANEIRO} (IFRJ)

\begin{abstract}
Distance education is a teaching modality in full expansion due to its capillarity and capacity for innovation. However, the design of a distance course requires the wide use of Information and Communication Technologies (ICT) and demands new formats that embrace interactivity. This article contextualizes the production of Learning Objects (LO) in Distance Education (DE) of Federal Institutes. In order to identify quality standards considered in the design of LOs, a qualitative analysis was carried out using documentary and bibliographic research through a bibliometric study, followed by data collection of 36 semi-structured interviews with students, technicians and

\footnotetext{
${ }^{1}$ Mestre em Gestão e Estratégia pela Universidade Federal Rural do Rio de Janeiro (UFRRJ). Graduada em Rádio e Televisão pela Universidade Federal de Minas Gerais (UFMG). Técnica em Audiovisual no Instituto Federal do Rio de Janeiro (IFRJ). E-mail:ligiamssouza@gmail.com

${ }^{2}$ Doutor em Engenharia de Produção pela Universidade Federal Rural do Rio de Janeiro (UFRRJ). Graduado em Administração pela Faculdade Moraes Júnior (FMJ). Professor Associado II na Universidade Federal Rural do Rio de Janeiro (UFRRJ).
} 
distance education managers in the federal network. Using the case study and a content analysis technique as a method, the following results were achieved: (a) making a diagnosis about the problem; (b) recommendations for improvements; (c) elaboration of an action plan to implement quality standards for the video classes production to the Virtual Teaching and Learning Environment of the Federal Institute of Science and Technology Education of Rio de Janeiro (IFRJ). In this article, we discuss achieved results.

Keywords: E-learning. Quality control. Learning object. Standard guide. Videoclass. ICT. 


\section{INTRODUÇÃO}

As tecnologias da informação e comunicação (TIC) revolucionaram a organização social nos últimos anos, tendo reflexo evidente sobre a educação. A valorização da ação coletiva, segundo Lévy (2003), desenvolve-se em forma de inteligência coletiva que é “[...] distribuída por toda parte, incessantemente valorizada, coordenada em tempo real, que resulta em uma mobilização efetiva das competências". Essa nova forma de inteligência busca reconhecer as habilidades dos indivíduos e coordená-las por meio da utilização das TIC. A convergência é não apenas tecnológica, mas também cultural, e acontece no campo semântico, ou seja, na maneira como lidamos com os meios digitais e como eles afetam o nosso dia a dia e ressignificam nossa vida. A pandemia do Covid-19 evidenciou essa relação entre a tecnologia e as relações sociais na medida em que passamos a trabalhar, estudar, comprar e conviver exclusivamente on-line. A EaD, utilizando-se dessas novas tecnologias, tem modificado o ambiente educacional, como modalidade condizente com os novos tempos em termos econômicos, políticos, demográficos, tecnológicos e sociais (SANTOS, 2016). A criação de um novo universo envolvendo o público de maneira a criar comunidades ativas de conhecimento permeia diretamente o campo educacional, especialmente a educação a distância. O Decreto $n^{\circ}$ 9.057/2017, em seu artigo $1^{\circ}$, assim define a educação a distância como segue:

\footnotetext{
Art. $1^{\circ}$ Para os fins deste Decreto, considera-se educação a distância a modalidade educacional na qual a mediação didático-pedagógica nos processos de ensino e aprendizagem ocorra com a utilização de meios e tecnologias de informação e comunicação, com pessoal qualificado, com políticas de acesso, com acompanhamento e avaliação compatíveis, entre outros, e desenvolva atividades educativas por estudantes e profissionais da educação que estejam em lugares e tempos diversos. (BRASIL, 2017).
}

Este artigo relata a investigação sobre como se dá a produção de objetos de aprendizagem que embasam a mediação didático-pedagógica no âmbito de instituições de ensino tecnológico. A pesquisa ocorreu a partir de um estudo de caso que visou estabelecer as principais diretrizes que norteiam a gestão da qualidade na educação a distância, especialmente na produção de objetos de aprendizagem (OA). A expressão "objeto de aprendizagem" foi cunhada por Wayne Hodgins em 1994 para definir a programação orientada a objetos e seu reuso na área de computação. A conotação original tinha como foco a criação de recursos educacionais personalizados, mas Wiley redefiniu OA como “[...] recurso digital que pode ser reutilizado para apoiar a aprendizagem" (WILEY, 2000). Entre os vários objetos de aprendizagem comumente usados nas instituições de ensino superior (IE), encontramos: 
programa de disciplina; programa do curso; palestras; slides ou anotações de palestras; tutoriais; trabalho prático; questionários; textos para tradução; vídeo e áudio para aprendizado de línguas estrangeiras; videoaulas; vídeos interativos; produtos de realidade virtual; jogos; e-books; e até mesmo um simples acesso à plataforma virtual. Entretanto, nem sempre há padronização na construção desses objetos de aprendizagem para o ambiente virtual das instituições federais. Dessa forma, chegamos na pergunta principal que motivou a investigação: "Que padrões cabem na construção de objetos de aprendizagem para uma educação a distância visando garantir a melhoria contínua da qualidade?"

\section{DESENVOLVIMENTO}

Nesta seção falaremos sobre o objetivo central e proposições colocadas pela pesquisa. Em seguida, descreveremos a fundamentação teórica elaborada a partir dos resultados bibliométricos que definiram os conceitos norteadores do trabalho (estado da arte) sobre a gestão da qualidade na educação a distância. Também descreveremos a metodologia de pesquisa utilizada e por fim, discutiremos os resultados obtidos.

\subsection{OBJETIVO/PROPOSTA}

A pesquisa consistiu na busca por padronização dos processos de construção de objetos de aprendizagem, a fim de fomentar a criação de uma cultura da qualidade na Diretoria EaD, bem como subsidiar os docentes do Instituto Federal de Educação, Ciência e Tecnologia do Rio de Janeiro (IFRJ) no fornecimento de instrumentos de consulta. Dessa maneira, contribui com duas metas relativas a processos internos previstas no Mapa Estratégico 2017-2021 da instituição pesquisada: promover a cultura de otimizar os processos de trabalho e consolidar a educação a distância nos diferentes níveis e modalidades de ensino. Assim, ficou definido como o objetivo final da pesquisa identificar os fatores de qualidade apropriados para a elaboração de um guia de padronização do desenvolvimento de objetos de aprendizagem (OA) nos cursos de educação a distância oferecidos pelo IFRJ, a fim de subsidiar a melhoria contínua.

\subsection{FUNDAMENTAÇÃO TEÓRICA}

A gestão da qualidade total (GQT) tornou-se uma arma estratégica para avaliar a concorrência, considerando cenários externos na definição de projetos e produtos em consonância com as necessidades do mercado, sendo estratégico também definir quais 


\section{ARTIGO}

INOVAÇÃo

dimensões da qualidade são essenciais para a organização (GOMES, 2004, p.17). Juran e Gryna (1993) elencam três pontos fundamentais para a gestão da qualidade, formando uma trilogia de controle da qualidade, que seria um processo cíclico de planejar, controlar e melhorar. A EaD pode ser considerada um produto tipo "serviço", e os cursos EaD se encaixam na classificação de serviços de massa. Estes, de acordo com Oliveira (2017, p. 47), têm características opostas aos serviços profissionais, ou seja, são altamente padronizados, com pouca participação/contato com o cliente, não personalizados (pouca variabilidade) e têm, em geral, curta duração. Como exemplos de serviços de massa podem-se citar os caixas bancários 24 horas e os cursos de educação a distância. Para decifrar a razão pela qual alguns cursos de educação a distância falham enquanto outros obtêm sucesso, Rovai e Downey (2010) apresentam uma série de fatores determinantes, tais como: planejamento; marketing e recrutamento; administração financeira; garantia de qualidade; retenção de alunos; desenvolvimento do corpo docente; design e pedagogia dos cursos online. De acordo com os autores, a garantia da qualidade deve ser baseada no monitoramento e melhoria contínua dos serviços oferecidos e dos currículos online, visando satisfazer as metas do programa educacional e ir ao encontro das necessidades dos alunos. Uma estratégia para alcançar a garantia de qualidade seria desenvolver uma ampla gama de processos, incluindo a seleção e qualificação da equipe, visando atender aos alunos em todas as demandas (on e off-line). Os autores concluem que alguns cursos falham por não gastar tempo suficiente na preparação do curso, na criação do design instrucional. De acordo com estes autores os problemas de qualidade ocorrem " [...] quando os cursos presenciais são apresentados em versões online com pouca ou nenhuma adaptação e quando professores são estimulados a desenvolver e apresentá-los sem preparação prévia ou experiência mínima para fazê-lo (ROVAI; DOWNEY, 2010, p. 145-147).

Ginns e Ellis (2009) estudaram a influência de cursos EaD no Reino Unido em cursos de graduação presenciais que ofertavam parte de seu currículo via educação a distância e concluíram que os itens que proporcionaram sucesso nessa empreitada seriam: uma plataforma de TI estável e robusta; equipe de suporte que responda aos alunos prontamente via e-mail e telefone; corpo docente que consiga integrar o aprendizado das atividades on-line aos currículos e aos objetivos do curso. Killedar (2008) afirma que o conceito de qualidade total varia de acordo com a percepção do avaliador e que na busca por uma acepção do termo é imprescindível entrevistar múltiplos agentes do processo. Em sua pesquisa, realizada na Índia, Killedar entrevistou tutores, experts em $\mathrm{EaD}$ e estudantes. Concluiu que entre os que avaliavam mal os cursos online, faltava serviço de tutoria e suporte técnico. Muitos estudantes sofriam também falta de infraestrutura básica em suas residências (Internet, eletricidade). A cultura institucional 
afeta todos os processos e procedimentos que balizam a estratégia voltada à qualidade. Essa cultura integra valores, crenças e regras de comportamento que nem sempre aparecem diretamente, mas surgem por meio dos resultados alcançados. Assim, a fim de implementar a gestão da qualidade nesses ambientes, é necessário contar com o comprometimento das lideranças desde o princípio. Na educação, a GQT tem papel significante em empoderar também a equipe para melhorar o conteúdo e as metodologias de ensino.

Militaru, Ungureanu e Chenic (2013) definem os clientes da educação entre internos e externos, em um cenário cujo produto representa a educação ofertada ao estudante, conforme a tipologia para clientes definida pelos autores: O primeiro cliente é o estudante, que se beneficia do produto (educação recebida) por toda a sua vida. O segundo cliente é representado pelos pais ou responsáveis, pois eles vão usar esse produto (especialmente quando a educação envolve gastos). O terceiro cliente é representado pelos futuros empregadores, que vão pagar para obter o benefício da educação recebida pelos estudantes. O quarto cliente é a sociedade ou comunidade, representada pelas organizações governamentais que contribuem com os custos da educação e esperam que o estudante, quando se tornar adulto, seja ativo e pague seus impostos ao governo.

Algumas características diferenciam as IES tradicionais daquelas que já introduziram os princípios da GQT: otimização das atividades nas unidades administrativas; equipes familiarizadas com os padrões de qualidade a serem alcançados; existência de um registro escrito dos procedimentos para ajudar a organizar a atividade educativa como um todo. Neste ponto, nossa pesquisa encontra sua missão de alinhamento horizontal para que ocorra um entendimento vertical do que vem a ser a política de qualidade da IE com relação a seus objetos de aprendizagem: criar um comando único para todas as atividades e procedimentos.

\subsection{MÉTODO DE PESQUISA}

Trata-se de um estudo de caso, realizado nas coordenações, diretorias, núcleos, polos, centros de referência e campi EaD que administram a modalidade nas instituições de ensino superior federais. É uma pesquisa de natureza exploratória e descritiva, de abordagem qualitativa, com a intenção de reunir dados para a construção de um guia de produção de videoaulas. Essa pesquisa também é aplicada, pois tem como "característica fundamental o interesse na aplicação, utilização e consequências práticas dos conhecimentos" (GIL, 2008, p. 27). A coleta de dados foi empreendida através de pesquisas bibliográfica, documental, 
observacional participante e de entrevistas semiestruturadas. Foi sistematizado o estado da arte para conhecimento do campo da qualidade relacionado à educação à distância.

O estudo delimitou-se às questões da qualidade na educação a distância no que tange à produção de objetos de aprendizagem no planejamento pedagógico para Ambiente Virtual de Ensino e Aprendizagem (AVEA), no que se refere ao ensino médio técnico, tecnológico e à graduação. $\mathrm{O}$ aparato teórico sustentou a fase exploratória, desenvolvida através da realização de 36 entrevistas com alunos, gestores e técnicos administrativos da EaD da Rede Federal de Educação Profissional, Científica e Tecnológica. Geograficamente, a pesquisa abrangeu seis estados brasileiros: Rio de Janeiro, São Paulo, Minas Gerais, Espírito Santo, Rio Grande do Norte e Paraíba. A pesquisa bibliográfica foi realizada a partir da técnica da bibliometria, utilizando as bases de dados Scopus, Web of Science e ScienceDirect. A escolha dessas bases se deu pela abrangência e interdisciplinaridade destas, estando diretamente relacionada à área de interesse do estudo: gestão da qualidade na educação a distância. Quanto ao recorte temporal, foram escolhidos os meses de maio e junho de 2018, levando-se em consideração, no entanto, publicações dos últimos dez anos, abrangendo o período de 2008 a 2018. As buscas foram feitas entre fevereiro e maio de 2018. O mapa da metodologia de pesquisa (Fig. 1) resume o caminho metodológico iniciado pela pesquisa bibliométrica.

Figura 1 - Mapa conceitual da metodologia de pesquisa

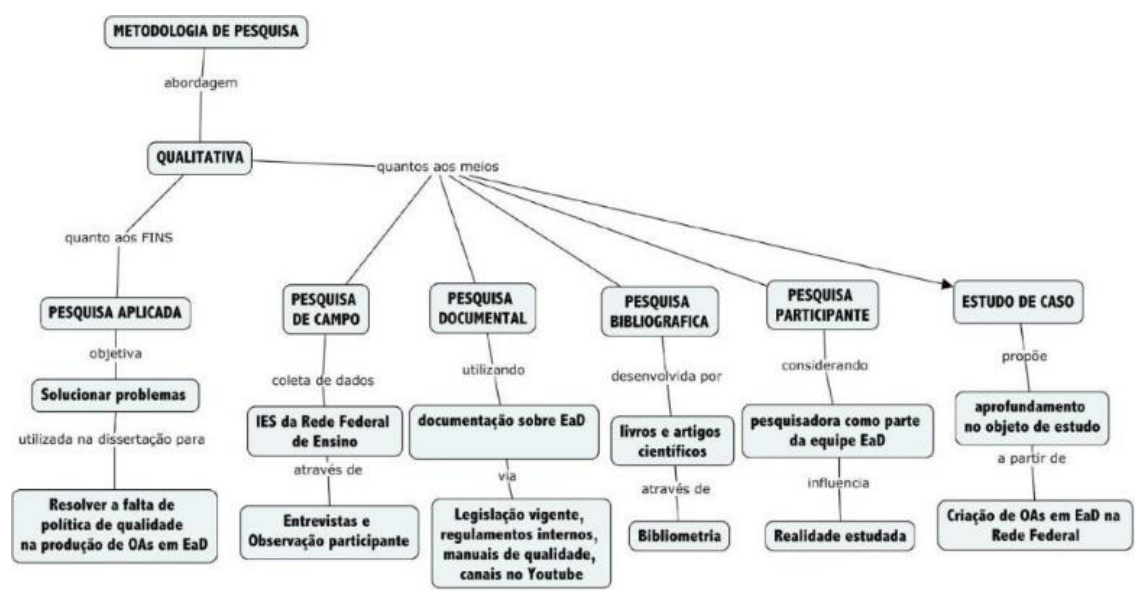

Fonte: Elaboração própria (2018)

A pesquisa documental foi realizada através da análise de documentação institucional, tais como editais, regimentos, regulamentos, formulários e manuais, com a intenção de identificar todas as atividades desenvolvidas pela a EaD. Foram também consultados a 
legislação específica, portais institucionais, ambientes virtuais de ensino e aprendizagem e canais de vídeo on-line das IES estudadas.

A pesquisa de campo englobou a realização de entrevistas semiestruturadas e observação participante. A observação participante deve-se ao ambiente organizacional em que a pesquisadora se insere (Diretoria de Educação a Distância) e atividades que exerce. As entrevistas foram realizadas com 12 gestores $\mathrm{EaD}, 12$ técnicos administrativos educacionais e 12 estudantes EaD. Com duração média de 30 minutos, as entrevistas foram gravadas com aparelho celular smartphone, depois transcritas e analisadas. Além da gravação foram utilizadas tabelas de preenchimento de dados e outros recursos de anotação.

A seleção dos sujeitos da pesquisa foi definida pela variabilidade da escolha de maneira a incluir todos os agentes do processo de criação de objetos de aprendizagem para EaD, ou seja, aqueles que coordenam e idealizam, os que projetam e operacionalizam e os que recebem e utilizam. Foi levada em consideração também a característica básica de uma equipe EaD que é ser multidisciplinar e tecnológica. Essa visão foi fundamental para elaboração das perguntas visando compreender o fenômeno estudado e atender às necessidades da pesquisa.

Os sujeitos da pesquisa foram assim definidos: GESTOR: gestores de polos, núcleos, campus e diretorias de EaD na Rede Federal; TÉCNICO: técnicos em audiovisual, tecnólogos em multimeios, técnicos em TI ou analistas de TI, vinculados a produção e controle de objetos de aprendizagem da plataforma Moodle das IFE; ALUNO: alunos vinculados a cursos EaD e que utilizem a plataforma Moodle das IE.

\subsection{DISCUSSÃO DOS RESULTADOS}

Para tratamento dos dados foi utilizada a análise de conteúdo e sua técnica de categorização temática, sugerida por Bardin (2011). Conforme as entrevistas foram transcritas, analisadas e classificadas dentro de categorias e os dados foram combinados usando tabelas Excel, chegamos a uma visão global do perfil dos entrevistados, que é apresentada brevemente na Tabela 1. 
Tabela 1 - Perfil dos entrevistados

\begin{tabular}{|c|c|c|c|c|}
\hline Função & Formação Acadêmica & $\begin{array}{l}\text { Tempo } \\
\text { na IES } \\
\text { (Anos) } \\
\end{array}$ & $\begin{array}{c}\text { Tempo } \\
\text { na EaD } \\
\text { (Anos) }\end{array}$ & Localização \\
\hline Gestor 1 & Mestrado em Pedagogia & 11 & 08 & Natal-RN \\
\hline Gestor 2 & Mestrado emAdministração & 14 & 14 & São Paulo-SP \\
\hline Gestor 3 & Mestrado em Pedagogia & 08 & 10 & Rio de Janeiro-RJ \\
\hline Gestor 4 & Mestrado em Pedagogia & 07 & 17 & Volta Redonda-RJ \\
\hline Gestor 5 & Mestrado em Ciências Biológicas & 08 & 08 & Pinheiral-RJ \\
\hline Gestor 6 & Mestrado em Administração & 03 & 03 & Niterói-RJ \\
\hline Gestor 7 & Doutorado em Gestão em Saúde & 05 & 05 & Pinheiral-RJ \\
\hline Gestor 8 & Graduação em Administração & 15 & 15 & Rio de Janeiro-RJ \\
\hline Gestor 9 & Mestrado em Letras & 10 & 8 & Resende-RJ \\
\hline Gestor 10 & Mestrado em Pedagogia & 04 & 10 & Belford Roxo-RJ \\
\hline Gestor 11 & Mestrado em Matemática & 02 & 01 & $\begin{array}{l}\text { São João de } \\
\text { Meriti-RJ }\end{array}$ \\
\hline Gestor 12 & Especialização em Enfermagem & 04 & 04 & Pinheiral-RJ \\
\hline Técnico 1 & Graduação em Pedagogia & 06 & 03 & $\begin{array}{l}\text { Montes Claros- } \\
\text { MG }\end{array}$ \\
\hline Técnico 2 & $\begin{array}{l}\text { Graduação em Análise de } \\
\text { Sistemas }\end{array}$ & 05 & 05 & João Pessoa-PB \\
\hline Técnico 3 & Pós-graduação em Pedagogia & 10 & 10 & Volta Redonda-RJ \\
\hline Técnico 4 & Pós-graduação em Computação & 06 & 06 & Pinheiral-RJ \\
\hline Técnico 5 & Graduação em Ciências Contábeis & 03 & 03 & Pinheiral-RJ \\
\hline Técnico 6 & Mestrado em Pedagogia & 02 & 03 & Rio de Janeiro-RJ \\
\hline Técnico 7 & Pós-graduação em Informática & 08 & 02 & Pinheiral-RJ \\
\hline Técnico 8 & Pós Graduação em Letras & 07 & 01 & Rio de Janeiro-RJ \\
\hline Técnico 9 & Mestrado em Turismo & 03 & 07 & Rio de Janeiro-RJ \\
\hline Técnico 10 & Graduação em Audiovisual & 08 & 11 & Natal-RN \\
\hline Técnico 11 & Mestrado em Audiovisual & 07 & 05 & São Paulo-SP \\
\hline Técnico 12 & Mestrado em Letras & 02 & 02 & São Paulo-SP \\
\hline Estudante 1 & Especialização em Libras & - & - & Itamarangiba-MG \\
\hline Estudante 2 & Especialização em Artes Visuais & - & - & PiúmaES \\
\hline
\end{tabular}




\begin{tabular}{l|l|c|c|l}
\hline Estudante 3 & Tecnólogo em Gestão de Turismo & - & - & Niterói-RJ \\
\hline Estudante 4 & Licenciatura em Artes Visuais & - & - & $\begin{array}{l}\text { Domingos } \\
\text { Martins-ES }\end{array}$ \\
\hline Estudante 5 & $\begin{array}{l}\text { Técnico em Agente Comunitário } \\
\text { de Saúde }\end{array}$ & - & - & $\begin{array}{l}\text { Complexo do } \\
\text { Alemão-RJ }\end{array}$ \\
\hline Estudante 6 & $\begin{array}{l}\text { Técnico em Agente Comunitário } \\
\text { de Saúde }\end{array}$ & - & - & $\begin{array}{l}\text { Volta Redonda- } \\
\text { RJ }\end{array}$ \\
\hline Estudante 7 & Técnico em Secretaria Escolar & - & - & Volta Redonda-RJ \\
\hline Estudante 8 & Especialização em Língua Inglesa & - & - & Rio de Janeiro RJ \\
\hline Estudante 9 & Bacharelado em Letras & - & - & São Paulo-SP \\
\hline Estudante 10 & Tecnólogo em Gestão de Turismo & - & - & Rio de Janeiro-RJ \\
\hline Estudante 11 & Bacharelado em Teologia & - & - & Maringá-PR \\
\hline Estudante 12 & Bacharelado em Ciências Contábeis & - & - & Rio de Janeiro-RJ \\
\hline
\end{tabular}

Fonte: Elaboração própria

A partir da transcrição das entrevistas em profundidade, foi realizada a análise de conteúdo (BARDIN, 2011) em que foi aplicada esta metodologia para construir categorias de análise temáticas. Foi realizada a tabulação dos dados utilizando uma planilha do software Excel para cada um dos perfis estudados. As planilhas foram alinhadas e nelas foram organizadas todas as respostas dos entrevistados a cada pergunta do roteiro. Foi feita então a análise categorial através de interpretação qualitativa a partir do cruzamento de dados empíricos (opiniões dos 3 perfis estudados). Assim, foram definidas as categorias e subcategorias estratificadas em grade aberta (derivantes do roteiro) e fechada (derivantes da repetição de palavras e temas nas entrevistas). Foi elaborado, então, um total de 7 categorias de análise para compor a matriz inicial (Figura 2 - Matriz de Categorias de Análise).

Figura 2 - Matriz de Categorias de Análise

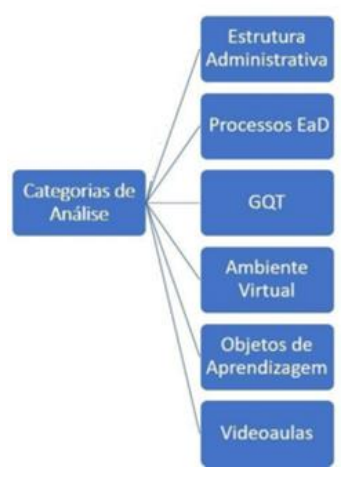

Fonte: Elaboração própria (2018) 


\section{ARTIGO}

Através da compilação dos dados e da definição da matriz de categorias de análise (estrutura administrativa; gestão de processos em EaD; gestão da qualidade total; Ambiente Virtual de Ensino e Aprendizagem; objetos de aprendizagem; produção de videoaulas), partiuse para o aprofundamento do estudo de cada categoria, gerando novas categorias ou subcategorias visando cobrir as temáticas à luz da literatura levantada. A partir desse momento foi utilizada a grade mista, que combina a grade aberta (categorias que vieram da literatura) com a grade fechada (categorias que submergiram a partir da análise do conteúdo das entrevistas). O quadro 1 demonstra as categorias, subcategorias e os principais resultados.

Quadro 1 - Matriz de Categorias de Análise

\begin{tabular}{|c|c|c|}
\hline Categoria da matriz & Subcategoria & Principais resultados \\
\hline \multirow[t]{4}{*}{ Estrutura administrativa } & Estrutura formal & 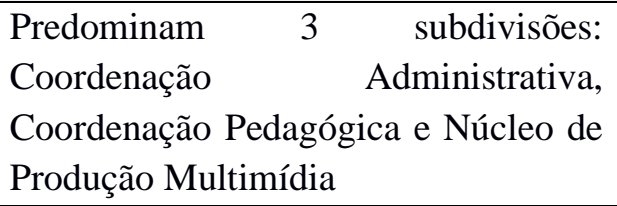 \\
\hline & Infraestrutura & $\begin{array}{l}\text { Integração da EaD com as demais áreas } \\
\text { estratégicas da instituição; Ambiente } \\
\text { Virtual de Ensino e Aprendizagem } \\
\text { integrado aos sistemas acadêmicos e de } \\
\text { TI }\end{array}$ \\
\hline & Formação da equipe $\mathrm{EaD}$ & $\begin{array}{l}\text { Multidisciplinaridade, alta capacidade } \\
\text { técnica }\end{array}$ \\
\hline & $\begin{array}{l}\text { Capacitação profissional da } \\
\text { equipe } \mathrm{EaD}\end{array}$ & $\begin{array}{l}\text { Cooperativismo; Trabalho em equipe; } \\
\text { Treinamento no ambiente de trabalho; } \\
\text { Formação profissional específica em } \\
\text { EaD leva à melhoria dos Ambientes } \\
\text { Virtuais de Ensino e Aprendizagem e } \\
\text { do relacionamento entre docentes e } \\
\text { estudantes / feedback }\end{array}$ \\
\hline \multirow[t]{4}{*}{$\begin{array}{l}\text { Gestão de processos em } \\
\text { EaD }\end{array}$} & $\begin{array}{l}\text { Conceito sobre gestão de } \\
\text { processos emitido pelos } \\
\text { entrevistados }\end{array}$ & $\begin{array}{l}\text { Desconhecimento sobre gestão de } \\
\text { processos e seu conteúdo por quem não } \\
\text { é formado na área administrativa }\end{array}$ \\
\hline & $\begin{array}{l}\text { Existência ou não de gestão } \\
\text { de processos na unidade } \\
\text { administrativa EaD }\end{array}$ & $\begin{array}{l}\text { Não existência de gestão de processos } \\
\text { nas unidades administrativas EaD }\end{array}$ \\
\hline & $\begin{array}{l}\text { Expectativa a respeito da } \\
\text { implementação da gestão de } \\
\text { processos na unidade } \\
\text { administrativa }\end{array}$ & $\begin{array}{l}\text { Baixa devido desconhecimento sobre a } \\
\text { gestão de processos e aplicações }\end{array}$ \\
\hline & $\begin{array}{l}\text { Responsáveis pela } \\
\text { implementação }\end{array}$ & $\begin{array}{l}\text { Na visão geral não compete a gestores } \\
\text { educacionais ou docentes. Visão } \\
\text { hierarquizada da implementação GP }\end{array}$ \\
\hline
\end{tabular}




\begin{tabular}{|c|c|c|}
\hline \multirow[t]{4}{*}{ Gestão da qualidade total } & Conceito & $\begin{array}{l}\text { Gestores entendem a GQT, docentes } \\
\text { acreditam ser incompatível com a área } \\
\text { da educação, técnicos a relacionam } \\
\text { com a TI }\end{array}$ \\
\hline & Importância & $\begin{array}{l}\text { Consenso de que deve ser implantada } \\
\text { em todo ambiente organizacional }\end{array}$ \\
\hline & Feedback & $\begin{array}{l}\text { Valorizado especialmente por técnicos } \\
\text { e alunos }\end{array}$ \\
\hline & $\begin{array}{l}\text { Melhoria contínua ou } \\
\text { conformidade }\end{array}$ & $\begin{array}{l}\text { A melhoria contínua depende } \\
\text { principalmente no bom funcionamento } \\
\text { dos sistemas de TI, da plataforma } \\
\text { virtual de ensino e aprendizagem e da } \\
\text { construção de objetos de aprendizagem }\end{array}$ \\
\hline \multirow[t]{5}{*}{$\begin{array}{l}\text { Ambiente Virtual de } \\
\text { Ensino e Aprendizagem }\end{array}$} & Atendimento & $\begin{array}{l}\text { Coordenação de curso disponível, uma } \\
\text { equipe de TI capacitada e tutores } \\
\text { habilitados }\end{array}$ \\
\hline & Infraestrutura & $\begin{array}{l}\text { Agilidade do sistema e disponibilidade } \\
\text { do material para diversas } \\
\text { mídias/formatos }\end{array}$ \\
\hline & Material didático & $\begin{array}{l}\text { E-books, livros físicos, fóruns } \\
\text { interativos, bibliotecas virtuais, } \\
\text { videoaulas. Viabilizar opções } \\
\text { fuffline é } \\
\text { fundamental }\end{array}$ \\
\hline & Avaliação & $\begin{array}{l}\text { Há falta de correspondência entre o } \\
\text { conteúdo apresentado e conteúdo } \\
\text { avaliado }\end{array}$ \\
\hline & Feedback & $\begin{array}{l}\text { Realizar avaliações periódicas do curso } \\
\text { e do Ambiente Virtual de Ensino e } \\
\text { Aprendizagem é fundamental para } \\
\text { todos os públicos pequisados }\end{array}$ \\
\hline $\begin{array}{l}\text { Objetos } \\
\text { Aprendizagem }\end{array}$ & Videoaula & $\begin{array}{l}\text { Formato ideal: curto, máximo } 20 \\
\text { minutos, utilizar recursos técnicos } \\
\text { variados, adequar para diversos } \\
\text { aparelhos, dividir tema em subtemas }\end{array}$ \\
\hline
\end{tabular}

Fonte: Elaboração própria (2021)

\section{CONCLUSÕES}

A EaD tem colaborado com a inclusão de estudantes na Rede Federal, pessoas sem outra oportunidade acadêmica, seja por questões sanitárias, econômicas, geográficas, ou por mera falta de infraestrutura que é a realidade de muitos municípios brasileiros, especialmente diante de constantes cortes de repasses no investimento público para a educação a partir da Proposta de Emenda à Constituição (PEC) 22/2019 (BRASIL, 2019). Dentro dessa perspectiva, o 


\section{ARTIGO}

INOVAÇÃo

objetivo final dessa pesquisa foi alcançado com a construção de um guia de padronização para produção de videoaulas para desenvolvimento de objetos de aprendizagem nos cursos de educação a distância oferecidos pelo IFRJ, buscando a melhoria contínua na unidade de ensino pesquisada.

Como parte desse processo, o primeiro objetivo intermediário alcançado foi a realização do levantamento da real situação da EaD quanto à qualidade na construção de objetos de aprendizagem em educação a distância no IFRJ, realizado através da análise do material coletado a partir das entrevistas realizadas com doze técnicos, doze gestores e doze alunos de institutos federais, tendo sido avaliados nesse processo sete dos quinze campi do IFRJ, além de outras instituições de seis diferentes estados brasileiros.

O segundo objetivo intermediário alcançado foi a identificação das falhas em termos de qualidade na construção destes objetos de aprendizagem a partir dos depoimentos levantados, sendo identificadas pelos entrevistados como principais deficiências na produção de videoaulas para ensino médio e graduação: falta de objetividade e dinamismo na apresentação da disciplina pelo docente; falta de material gráfico complementar; longo tempo de duração da videoaula; falta de adequação do formato e linguagem videográfica à regionalidades e realidade do aluno em termos tecnológico e sociocultural.

Com base nessas falhas encontradas realizou-se levantamento e apresentação de fatores de qualidade pertinentes à realidade do IFRJ capazes de apoiar a produção de videoaulas e a capacitação dos docentes. Desse modo, concluiu-se os objetivos intermediários da pesquisa, concretizados através da elaboração e implantação de um plano de ação para a infraestrutura de apoio à funcionalidade para a construção de objetos de aprendizagem (OA) na educação a distância (EaD) do Instituto Federal de Educação, Ciência e Tecnologia do Rio de Janeiro (IFRJ).

A principal contribuição deste trabalho foi a elaboração do plano de ação realizado em quatro etapas. A primeira constituiu-se no diagnóstico sobre a situação em que se encontravam as diretrizes e procedimentos de apoio à elaboração de objetos de aprendizagens da educação a distância (EAD), comumente utilizados no desenvolvimento de videoaulas do IFRJ. Para isso, foi feita uma pesquisa junto aos principais envolvidos nestas atividades, aplicando-se um roteiro de entrevista semiestruturado a 36 sujeitos, sendo eles: gestores de polos, núcleos, campus e Diretorias de EAD do IFRJ; técnicos em audiovisual, TI ou analistas de TI e tecnólogos em multimeios, todos vinculados à produção e controle de objetos de aprendizagem da plataforma Moodle das IFE; alunos usuários de cursos EaD. Neste momento, identificouse alguns elementos de padronização de qualidade mais apropriados resumidos no Guia de 
Produção de Videoaulas do IFRJ que foi publicado no website da instituição na sessão de Manuais EaD: (https://portal.ifrj.edu.br/ead/manuais). Na segunda etapa deste plano de ação, o Guia foi validado pela Diretoria Tecnológica de Ensino e Inovação (DTEIN). Tal documento institui as regras para a implementação de um padrão mínimo de qualidade no que tange à criação e videoaulas para o ambiente virtual de ensino e aprendizagem do IFRJ - Moodle (https://moodle.ifrj.edu.br/).

Na terceira etapa do plano de ação foi ofertado um curso de extensão de 60 horas intitulado "Produção de Videoaulas" no Ambiente Virtual de Ensino e Aprendizagem - AVEA do IFRJ. Na sua primeira edição, o curso contou com 36 docentes inscritos que se capacitaram para produzir videoaulas nos seus respectivos campi IFRJ. Neste curso, o Guia foi apresentado como livro texto e foi amplamente discutido e implementado com foco na formação docente para a utilização deste recurso pedagógico e tecnológico. Desde 2018 o curso já foi ofertado quatro vezes e foi aberto à comunidade externa, tendo alcançado aproximadamente duas mil pessoas em dezembro de 2020. Em março de 2021, o curso caminha para a sua quinta edição como capacitação on-line no formato de um curso MOOC (Massive Open Online Course ou Curso Online Aberto e Massivo).

A etapa quatro consistiu no desenvolvimento de oficinas presenciais sobre produção de videoaulas para divulgar o Guia de produção de videoaulas do IFRJ entre técnicos e docentes. Essa fase já aconteceu presencialmente em 2018-19, no entanto, a partir de 2020 foi interrompida por ocasião da pandemia Covid 19.

Dessa forma, a questão de pesquisa: com base na descrição da EaD no IFRJ, que padrões devem ser utilizados na construção de objetos de aprendizagem para a educação a distância do IFRJ de modo a buscar sempre a melhor qualidade? foi respondida com o lançamento e ampla utilização do Guia de produção de videoaulas do IFRJ, considerado uma inovação no âmbito institucional por inaugurar a criação de guias e manuais norteadores para a educação a distância no instituto. Após seu lançamento seguiram-se mais duas publicações: o Guia de ferramentas para uso de tecnologías, elaborado pela Diretoria Adjunta de Tecnologia e Inovação em Educação Profissional e Tecnológica (DTEIN), e outro guia para a elaboração de videoconferencias, elaborado pela Comunicação Geral de Comunicação Social (CGCom). Esses guias ofereceram diretrizes na confecção de objetos de aprendizagem para as Atividades Pedagógicas Não Presenciais (APNPs) instituídas em virtude da situação de pandemia de Covid-19, a partir de março de 2020.

Por meio do diagnóstico realizado foi possível descobrir a inexistência de padrões para qualquer tipo de objetos de aprendizagem no ambiente da $\mathrm{EaD}$, no qual cada docente, ao 
desenvolver suas videoaulas, o fazia à sua própria maneira. Essa lacuna contribuía para o surgimento de constantes falhas e erros no processo de transmissão do conhecimento e colocava em dúvida a qualidade dos objetos desenvolvidos. As soluções sociotécnicas formalizadas na concepção do Guia de produção de videoaulas foram recomendadas para todas as unidades de EaD do IFRJ, considerando que o estudo incluiu sujeitos envolvidos com as atividades de EaD de diferentes unidades do IFRJ, nas quais foram realizadas as pesquisas de campo, e que os processos dessas unidades são semelhantes, não devendo precisar de ajustes ou adaptações.

Outros benefícios obtidos com a pesquisa e desenvolvimento do trabalho, além das ações supracitadas, foram a busca pelo melhor atendimento ao aluno e pelo fortalecimento da EaD como modalidade presente na vida acadêmica, visando suprir as necessidades dos alunos incapacitados de frequentar cursos presenciais. 


\section{REFERÊNCIAS}

BARDIN, L. Análise de conteúdo. Lisboa: Edições 70, 2011.

BRASIL. Decreto n. 9.057, de 25 de maio de 2017. Regulamenta o art. 80 da Lei no 9.394, de 20 de dezembro de 1996, que estabelece as diretrizes e bases da educação nacional. Brasília, DF: Câmara dos Deputados, 2017. Disponível em: https://www2.camara.leg.br/legin/fed/decret/2017/decreto-9057-25-maio-2017-784941publicacaooriginal-152832-pe.html. Acesso em: 12 mar. 2018.

BRASIL. PEC 22/2019: Proposta de Emenda à Constituição no 22 de 2019. Altera o Ato das Disposições Constitucionais Transitórias, para fixar o valor mínimo a ser aplicado, anualmente, pelos Estados, pelo Distrito Federal e pelos Municípios, em ações e serviços públicos de saúde e em manutenção e desenvolvimento do ensino. Brasília, DF: Senado Federal, 2019. Disponível em: https://www25.senado.leg.br/web/atividade/materias//materia/135851. Acesso em: 12 fev. 2021.

GIL, Antonio Carlos. Como elaborar projetos de pesquisa. 4. ed. São Paulo: Atlas, 2008.

GINNS, P.; ELLIS, R. A. Evaluating the quality of e-learning at the degree level in the student experience of blended learning. British Journal of Educational Technology, London, v. 40, n. 4, p. 652-663, 2009.

GOMES, P. J. P. A evolução do conceito de qualidade: dos bens manufacturados aos serviços de informação. Cadernos BAD, Lisboa, n. 2, 2004. Disponível em:

https://www.bad.pt/publicacoes/index.php/cadernos/article/view/826. Acesso em: 15 jul. 2018.

JURAN, J. M.; GRYNA, F. M. Controle da qualidade: handbook. São Paulo: Makron Books, 1993.

KILLEDAR, M. Effectiveness of learning process using "web technology" in the distance learning system. Turkish online journal of distance education, v. 9, n. 4, art. 8, Oct. 2008. Disponível em: https://dergipark.org.tr/en/download/article-file/156305. Acesso em: 03 mar. 2021.

LÉVY, P. A inteligência coletiva: por uma antropologia do ciberespaço. 4. ed. São Paulo: Loyola, 2003.

MILITARU, M.; UNGUREANU, G.; CHENIC, A. S. The prospects of implementing the principles of Total Quality Management (TQM) in education. Procedia-Social and Behavioral Sciences, v. 93, p. 1138-1141, 2013.

OLIVEIRA, O. J. Curso básico de gestão da qualidade. São Paulo: Cengage, 2017.

ROVAI, A. P.; DOWNEY, J. R. Why some distance education programs fail while others succeed in a global environment. Internet and Higher Education, v. 13, n. 3, p. 141-147, June 2010. Disponível em: https://www.learntechlib.org/p/108384/. Acesso em: 20 maio 2019. 
SANTOS, E. Mídias e tecnologias na educação presencial e a distância. Rio de Janeiro: LTC, 2016.

WILEY, D. A. Learning object design and sequencing theory. Unpublished doctoral dissertation, Brigham Young University. 2000. Disponível em

http://www.reusability.org/read/chapters/wiley.doc. Acesso em 25 fev. 2021. 